\title{
PERSPECTIVAS ESTRUTURANTES: CONTRIBUIÇÕES DA NARRATOLOGIA PÓS-CLÁSSICA PARA O ESTUDO DA FOCALIZAÇÃO NARRATIVA
}

\section{STRUCTURE PERSPECTIVES: CONTRIBUTIONS OF POST- CLASSICAL NARRATOLOGY FOR THE STUDY OF FOCALIZATION}

\author{
Raquel Trentin Oliveira ${ }^{1}$
}

RESUMO: Focos narrativos complexos, como os preponderantes em O som e a fúria, de Faulkner, e Em busca do tempo perdido, de Proust, justificam, por si mesmos, o reconhecimento da significância do processo de focalização em uma narrativa e a relevância de um estudo abrangente e aprofundado do tema, sem reduzi-lo a classificações superficiais e restritivas. Neste artigo, analiso criticamente alguns dos enfoques dados ao problema pela chamada narratologia pós-clássica (ainda pouco divulgada no Brasil), a qual, por meio do diálogo com outras áreas do saber, tem considerado a focalização como um processo dinâmico, resultante da interdependência dos atos de percepção, cognição e mediação semiótica.

PALAVRAS-CHAVE: Narratologia Pós-Clássica. Focalização. Dinamicidade Narrativa.

ABSTRACT: Complex viewpoints, as preponderant in The sound and the fury, by Faulkner, and in $\dot{A}$ la recherche $d u$ temps perdu, by Proust, justify the significance of the focusing process in a narrative. They also indicate the importance of a comprehensive and detailed study of this subject without reducing it to superficial and restrictive classifications. In this paper, I analyze some of the approaches given to this issue by the so-called post-classical narratology (little known in Brazil). Some of these approaches have considered focalization as a dynamic process resulting of the interdependence between acts of perception, cognition and semiotic mediation.

KEYWORDS: Post-Classical Narratology. Focalization. Narrative Dynamism.

\footnotetext{
1 Professora do Departamento de Letras Vernáculas e do Programa de Pós-Graduação em Letras, da Universidade Federal de Santa Maria/ RS. Trabalho resultante da pesquisa de pós-doutorado desenvolvida na Universidade de Coimbra, sob coordenação do Prof. Dr. Carlos Reis, apoiada pela Coordenação de Aperfeiçoamento de Pessoal de Nível Superior (CAPES).
} 


\section{PERSPECTIVAS ESTRUTURANTES: CONTRIBUIÇÕES DA NARRATOLOGIA PÓS- CLÁSSICA PARA O ESTUDO DA FOCALIZAÇÃO NARRATIVA}

Ao analisar o romance como gênero plurilíngue e pluriestilístico, Mikhail Bakhtin valorizava a "iniciativa ideológica e linguística" das pessoas ficcionais. Isto é, o autor, o narrador e a personagem, enquanto perspectivas individuais projetadas pela linguagem do romance, são, nas palavras do autor, "ideólogos em maior ou menor grau":

o discurso do autor, os discursos dos narradores, os gêneros intercalados, os discursos das personagens não passam de unidades básicas de composição com a ajuda das quais o plurilinguismo se introduz no romance. Cada um desses discursos admite uma variedade de vozes sociais e de diferentes ligações e correlações (sempre dialogizadas em maior ou menor grau) (BAKHTIN, 2002, p.75).

Em outras palavras, os pontos de vista expressos ou subjacentes ao romance, independentemente do nível em que aparecem, incorporam e acentuam eixos axiológicos próprios.

Sabemos, por outro lado, que boa parte dos estudos narrativos, sobretudo a narratologia estruturalista, acabou por negar tal implicação ideológica para examinar com mais rigor o comportamento das pessoas verbais na tessitura textual. Também a tradição romanesca, a certa altura, condenou a intervenção direta e a explicitação da ideologia do narrador onisciente, em nome de uma representação mais objetiva da realidade. Ambas as concepções idealizavam aproximar-se daquela visão impessoal, não-localizada, universal da ciência. O escritor norte-americano Henry James (1934/2003) consagrou-se por oferecer uma alternativa à onisciência do narrador, defendendo, isto sim, o aproveitamento da perspectiva da personagem interna à história, o que propiciaria a ilusão de realidade e preservaria a coerência de uma obra "auto-suficiente". 
Foi especialmente em relação à ilusão de realidade, projetada por meio da manipulação das funções narrativas de "mostrar" ou de "dizer", que as primeiras teorias do foco narrativo se posicionaram, como as de Pierce Lubbock (1921/1976) e de Norman Friedman (1967/2002). Uma voz dissonante nesse quadro foi a de Wayne Booth (1961/1980), por defender que as modulações técnicas são, em última instância, modulações das vozes do autor: para ele, o autor pode escolher disfarçar-se, mas não pode nunca escolher desaparecer. Isto é, representado ou não, onisciente ou não, digno de confiança ou não, o autor implícito (ou implicado) - atende sempre ao propósito de comunicar um conjunto de valores ao leitor.

Em contraposição, a abordagem do estruturalista Gérard Genette, em $O$ Discurso da narrativa (1972/1995), preocupa-se justamente com a obliteração de algumas distinções capitais na análise da narrativa, como a suposta entre autor e narrador, e entre temporalidade da história e temporalidade da narrativa. O grau de especificação e ênfase que Genette dá à focalização nesse texto faz com que seja referência incontornável em todos os estudos do assunto publicados posteriormente, como os de Mieke Bal (1985/2009) e outros mais recentes, que integram a chamada narratologia pós-clássica e expõem, na contramão dos estudos genettianos, as dimensões ideológicas e transliterárias da narrativa.

Pretendo, então, retomar alguns dos diálogos teóricos que se estabeleceram com Gérard Genette mais recentemente, na tentativa de contribuir para desterritorializar a noção de focalização assim como enraizada nos estudos narrativos tradicionais. Parto do pressuposto de que as classificações categóricas e dicotômicas restringem a operatividade do conceito e sua potencialidade funcional para a leitura da narrativa. Defendo, ao contrário, um sistema conceitual aberto, que permita múltiplas conexões e trânsitos - dependentes, é claro, das particularidades de cada obra.

Gérard Genette legou-nos um modelo teórico relativamente simples e útil, mas também algumas dicotomias e restrições um tanto polêmicas. Para ele, o estudo da narrativa deve partir da distinção entre modo e voz: isto é, "entre a pergunta qual é a personagem cujo ponto de vista orienta a perspectiva narrativa?, e esta bem distinta pergunta, "quem é o narrador", ou entre "quem vê" e "quem fala" (1995, p.184, grifo meu). Na sua abordagem, a focalização compreende uma restrição da informação no nível do discurso narrativo, de responsabilidade do narrador, em relação ao campo de visão de uma ou mais personagens da história. Se não há essa restrição, se o narrador demonstra saber mais do que a personagem, a narrativa é não-focalizada ou de focalização zero. Quando o narrador limita as informações narrativas ao que certa(s) personagem $(\mathrm{s})$ sabe $(\mathrm{m})$, sente $(\mathrm{m})$, pensa $(\mathrm{m})$, rende-se a uma focalização interna. Quando essa restrição não chega a revelar o mundo interno da personagem, permitindo ver apenas aspectos "superficiais e materialmente observáveis" (REIS; LOPES, 2002, p.168), trata-se de uma focalização externa. Assim, de acordo com Genette, "no existe personaje focalizador o focalizado: focalizado solo se puede aplicar al proprio relato, y focalizador, si se aplica a alguien, solo pude ser al que focaliza el relato, es decir, el narrador o, si se quiere sair de los procolos da ficción, el autor, tanto si delega en el narrador su poder de focalizar, o no, como si no lo hace" (1998, p.50). Isso afirmava Gérard Genette (1998, p.50) para refutar a tese de Mieke Bal (2009), segundo a qual todo enunciado narrativo compreende um sujeito focalizador e um objeto focalizado. Conforme Bal, o sujeito da focalização constitui o ponto de que se contemplam os elementos incluídos na narrativa e esse ponto pode corresponder tanto a um sujeito que está fora da história (focalização externa), quanto a um sujeito que faz parte dela (focalização interna).

A suposição de Genette de que a focalização restringe-se ao nível do discurso pode ser entendida como divergente do pressuposto do próprio autor de que é a personagem quem

Raquel Trentin Oliveira, Perspectivas estruturantes: contribuições da narratologia pós-clássica... 
vê/ percebe o mundo e é o narrador quem fala. Desse pressuposto resulta a noção de que um narrador autodiegético primeiro vive/percebe a história e depois a narra, ou de que um narrador pode falar em terceira pessoa aproveitando a percepção das personagens. Em tempos mais recentes, Seymor Chatman (1990) e Gerald Prince (2001), que afirmam concordar com a "abordagem restritiva" (PRINCE, 2001, p.43) de Genette, levaram tal dicotomia às últimas consequências, argumentando, no entanto, que só a personagem pode assumir a função de focalizadora, pois o narrador é um elemento do discurso e não da história, enquanto focalização é um elemento desta última ${ }^{2}$ (PRINCE, 2001, p.46).

Se aplicarmos essas noções ao romance Os Maias (1888), de Eça de Queirós, por exemplo, especificamente ao modo como Maria Eduarda é apresentada na narrativa, Carlos seria o focalizador na concepção de Prince, Chatman e Bal, pois é ele quem vê Maria, são suas sensações, pensamentos e sentimentos que a revelam ao leitor. Para Genette, o focalizador continua sendo o narrador heterodiegético de Os maias, que restringe provisoriamente a sua onisciência para acompanhar a percepção interna de Carlos sobre a irmã. Isto é, para Genette, a focalização requer a restrição ou não do discurso pelo narrador (ou mesmo pelo autor, como admitido por ele), à percepção das personagens que vivem na/a história. Já Prince e Chatman, assim como Bal, entendem focalização como o ato em si mesmo de perceber o mundo, mas, para os dois primeiros, tal ato é levado a cabo apenas pelas personagens no nível da história.

Outro teórico dos estudos narrativos mais recentes, James Phelan, respondendo diretamente a Prince e Chatman, escreve um texto intitulado "Why narrators can be focalizers?" (2001) e aponta como problema a restrição da focalização ou ao nível do discurso, ou ao da história. $\mathrm{O}$ autor deixa claro isso quando questiona o poder explanatório da distinção entre os dois níveis, afirmando tratar-se de um "constructo heurístico, mais do que uma lei natural, uma separação que inventamos para explicar nossa concepção de narrativa, não um intratável fenômeno que estabelece fronteiras impermeáveis entre o relato do narrador e as ações das personagens ${ }^{3}$ (2001, p.51). O mesmo questionamento atinge a distinção entre perceber e relatar: "A distinção entre percepção e narração - ou no caso do narrador homodiegético, entre percepção e rememoração - é, em última análise, impossível de manter sem reduzirmos todos os narradores a máquinas de narrar (Olá, meu nome é HAL e serei seu relator para esta narrativa)" 4 (PHELAN, 2001, p.57).

Realmente, concebendo a narrativa na sua relação com o conteúdo humano, é fácil reconhecer que tanto no nível do discurso quanto no nível da história, um sujeito é capaz de falar/ narrar e perceber/ ver, expressando um modelo do mundo de forma mais ou menos clara. Afinal, como é possível narrar sem ver ou sem dar a ver algo sobre o que se narra? Então, poderíamos reformular a pergunta de Genette: "quem é o agente narrativo que vê o que a personagem vê?". Isto é, pode ser a personagem que vê, mas é o narrador que vê o que a personagem vê. E poderíamos ir mais longe, se colocássemos nessa roda o autor e o leitor. De qualquer forma, é importante não esquecer que cada um faz isso em seu próprio nível, até porque, em tese, a personagem não pode focalizar a narrativa de cuja existência não está

\footnotetext{
${ }^{2}$ Nas palavras exatas de Prince: "The narrator - even an intradiegetic and homodiegetic - is never a focalizer [...] If the narrator is never a focalizer, it is simply because, qua narrator and regardless of his or her (homo or hetero, intra or extra) diegetic status and narratorial stance, s/he is never part of the diegesis s/he presents. Qua narrator, $\mathrm{s} / \mathrm{he}$ is an element of discourse and not story (of the narrating and not narrated) whereas focalization is an element of the latter"

3 Tradução minha para: "the story/discourse distinction is a heuristic construct rather than a natural law, something we've invented to aid our understanding of narrative, not an intractable phenomenon establishing impermeable boundaries between narrative commentary and character's actions".

4 "The distinction between perceiving and reporting - or in the case of homodiegetic narrators, between perceiving and remembering - is ultimately impossible to maintain unless we reduce all narrators to reporting machines (Hello, my name is HAL, and I will be your reporter for this narrative".
} 
ciente. Tal noção permite flexibilizar e reconectar aqueles aspectos que a abordagem estruturalista estratificatória modelou como independentes, sem perder de vista as nuances concernentes a cada estrato, já tão bem mapeadas pela mesma abordagem.

A rearticulação entre modo (perspectiva) e voz (narração) no estudo da focalização é defendida por diversos autores da narratologia contemporânea (MARGOLIN, 2009; HERMAN E VERVAEC, 2004; HERMAN, 2009). Manfred Jahn (1999) é um dos que mais desenvolveu essa ideia, em diálogo com a psicologia cognitiva. Nessa perspectiva, o autor discrimina, de forma abrangente mas não exaustiva, os indicadores da qualidade da focalização, resultantes da comunicação entre focalizador e objeto focalizado:

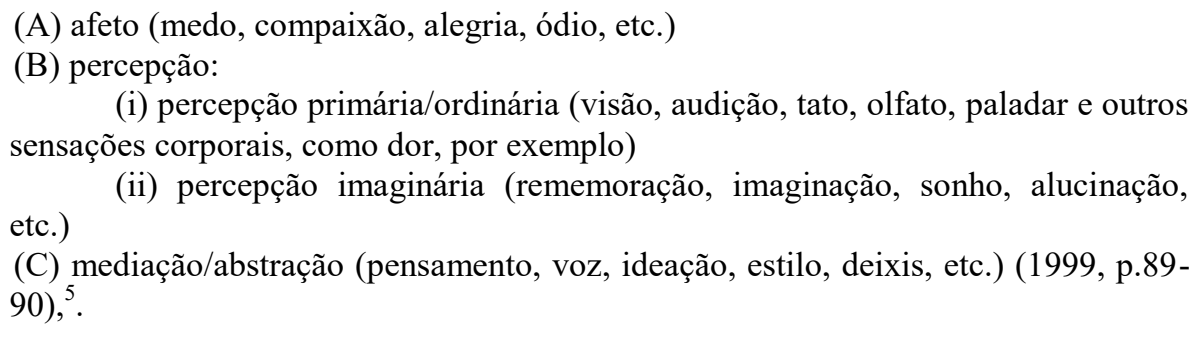

A interação entre modo e voz fica muito evidente pela inclusão da letra C nessa lista. Segundo o autor, tal inclusão é plausível, pois uma personagem, em princípio, é capaz de expressar-se na sua própria voz, como o narrador, e inclusive contar uma história; e o narrador também pode ser entendido como um ser pensante e agente da percepção. Com isso, Jahn defende a voz da personagem como um elemento da focalização, pois ela não só percebe o mundo a sua volta, mas também pode expressar, através do próprio discurso e estilo, a sua perspectiva. Mas o que mais nos interessa nesse elenco do autor, é a compreensão alargada do processo de focalização, que muitas vezes ficou restrito à percepção comum, ou mesmo confundido com uma simples tomada ótica. Além da consideração da emoção, Jahn destaca a percepção imaginária, que convive em uma relação de equivalência com a percepção ordinária. $\mathrm{O}$ autor justifica essa dinâmica pela constatação da psicologia cognitiva de que é frequentemente imposssível distinguir se a percepção é baseada num imput sensório "real", ou em processos imaginários, ou em uma combinação deles (1999) ${ }^{6}$.

III

Como nossa experiência de leitura permite inferir, o engajamento empático do leitor com as perspectivas implicadas no texto funciona como um dispositivo da focalização, ou melhor, a perspectiva do leitor interatua com as demais perspectivas. Num já referencial texto sobre o assunto, o pesquisador alemão Ansgar Nünning projeta claramente tal noção.

\footnotetext{
${ }^{5}$ (A) affect (fear, pity, joy, revulsion, etc.)

(B) perception:

(i) ordinary/primary/literal perception (vision, audition, touch, smell, taste, bodily sensation);

(ii) imaginary perception (recollection, imagination, dream, hallucination, etc.)

(C) conceptualization (thought, voice, ideation, style, deixis, etc.).

${ }^{6}$ Entendimento semelhante do conteúdo mental é apresentado por tendências da neurociência: "Do nosso encontro com um dado objeto não memorizamos apenas a sua estrutura visual, tal como é mapeada em imagens ópticas da retina. Também é necessário o que se segue: primeiro, os padrões sensório-motores associados à visão do objeto [...]; segundo, o padrão sensório-motor associado ao tacto e à manipulação do objecto (se for o caso); terceiro, o padrão sensório-motor resultante da evocação de recordações adquiridas anteriormente que são pertinentes para o objeto; quarto, os padrões sensório-motores ligados ao desencadear de emoções e sentimentos relativos ao objeto" (DAMÁSIO, 2010, p.170).
} 
Segundo Nünning, a perspectiva da personagem é regida pela totalidade de seus conhecimentos e crenças, intenções, traços psicológicos, atitudes, postura ideológica, sistema de valores e normas internalizadas. Em suma, abarca tudo o que existe na mente da personagem (2001, p.211). A mesma visão subjetiva do mundo pode ser atribuída ao narrador. "Assim como para cada personagem, o leitor pode construir uma perspectiva individual para o narrador, ao atribuir à voz que pronuncia o discurso idiossincrasias psicológicas, atitudes, normas e valores, um conjunto de propriedades mentais e um modelo do mundo" (idem, p.212). Das relações entre as perspectivas do narrador e das personagens e dos padrões de inter-relação estabelecidos resulta o que o autor chama de "structure perspective" (idem, p. 214), que traduzi, livremente, por perspectiva estruturante.

Assim, quanto maior o espectro de diferenças sociais, morais e ideológicas entre as várias perspectivas, mais diversificada e complexa é a perspectiva estruturante emergente. $\mathrm{O}$ modo como são combinadas e coordenadas, sintagmática e paradigmaticamente, permite estabelecer padrões de contrastes e correspondências. A estrutura será mais fechada e monológica quando todas as perspectivas em conjunto servirem para desenhar uma linha de convergência semântica. Será mais aberta e dialógica quando permanecerem discrepâncias inconciliáveis entre as perspectivas individuais. Para distinguir os sistemas resultantes, Nünning (2001, p.215-216) sugere quatro critérios: 1. o grau de ênfase dado à perspectiva de cada personagem; 2. a existência ou não de uma hierarquia de perspectivas entre as personagens e entre as personagens e o narrador; 3. o grau de individualização da perspectiva do narrador, de ingerência sobre as perspectivas das personagens e o consequente estabelecimento ou não de uma visão unificada do mundo; 4. no caso de o escopo de perspectivas não resultar em um sistema aberto, o grau de homogeneidade ou intersubjetividade derivado das várias perspectivas. A perspectiva estruturante, na medida em que implica a coordenação dos diversos pontos de vista das personagens e do(s) narrador(es), reenviaria, então, para a perspectiva do autor, enquanto fonte imaginária e epistêmica, reconfigurada pelo leitor. Mas é a atividade do último que Nünning ressalta. Apesar de dependente de propriedades textuais, a perspectiva estruturante não é inerente ao texto, mas construída pelo leitor individual durante o processo de leitura (NÜNNING, 2001). Assim, quanto mais diversificado o espectro de perspectivas maior a demanda sobre o leitor para coordená-lo.

É o leitor, portanto, que põe esse sistema dinâmico a funcionar, a partir de um ponto de vista móvel, múltiplo e parcial, como já nos ensinava Wolfgang Iser, exigente de uma constante atividade de síntese, correção e modificação (ISER, 1999). Ao detectar incongruências ou contradições entre as diversas perspectivas, o leitor é convidado a tomar uma postura frente a elas e para isso terá de fazer valer a sua própria perspectiva, não só como uma posição de leitura a ocupar, não só como aproximação ao leitor implícito, senão também como leitor real, com uma bagagem cultural e ideológica que o faz interagir com o texto, traçando uma relação tanto de encontro como de tensão entre o seu próprio mundo e o do texto (PIMENTEL, 2012). Sendo assim, posso pensar que a perspectiva estruturante, mesmo a mais fechada, não implica o engessamento semântico da narrativa, apresenta-se, ao contrário, como uma constante instável, propensa a diferentes agenciamentos e linhas de fuga.

Assim, o engajamento psicofísico do leitor com as diversas perspectivas em jogo na narrativa pode ser entendido como uma parte do processo de coordenação das mesmas e da tomada de uma posição individual frente às perspectivas estruturantes. Por exemplo, a narrativa, ao introduzir elementos dêiticos marcadores de temporalidade, como "agora", "então", "antes", depois", ativa o posicionamento subjetivo do leitor, transcendendo o domínio do representado e obrigando-lhe a engajar-se mentalmente no jogo representacional. "É essa interação de tempos - entre a objetivamente percebida (ou imaginada) linha do tempo narrativo e a nossa subjetivamente experimentada posição-no-tempo - que é tão altamente 
sugestiva e nos atrai para imergir em um continuum ficcional de eventos" ${ }^{7}$, como explicam Meister e Shönert (2009, p.22).

Numa perspectiva semelhante, Amy Coplan (2004), ao discutir o engajamento empático dos leitores com o texto narrativo, relatou uma série de relevantes estudos como evidências de que leitores tendem a adotar uma posição dentro da estrutura espaço-temporal das narrativas, baseados na posição dos focalizadores. Tais resultados indicam que há uma disposição no leitor para simular o ponto de vista do focalizador, o que corresponderia à disposição do nosso cérebro para simular um estado corporal que não está na realidade a acontecer em nosso organismo (cf. DECETY; JACKSON, 2006; DAMÁSIO, 2010).

Portanto, por meio da conexão empática, o leitor simularia a experiência de uma personagem, mas, por ter seus próprios pensamentos e emoções, sua experiência em geral envolve mais do que apenas simulação. O leitor entra numa relação de empatia com a personagem, mas também reage ao que é aprendido através da empatia e de informações a que tem acesso e as personagens não (COPLAN, 2001). Richard Guerrig (2001), no mesmo sentido, vai sugerir que por meio da interação com o texto, o leitor pode descobrir sua perspectiva externa, na medida em que as perspectivas representadas diferirem dos seus conhecimentos prévios, crenças ou expectativas. Ademais, a descoberta de novas perspectivas na narrativa pode interferir na sua avaliação de verdades do mundo real.

Então, como ficaria a recepção diante de narrativas que levam ao extremo a complexidade da focalização? Nossa tentativa de responder às perguntas "onde / quem / como é que ele/ ela sabe / reflete / informa - tem se tornado uma tarefa cada vez mais difícil. Não há uma única instância narrativa, mas sim, ele/ela é algo que está em fluxo e pode mudar ao longo da leitura: é uma função, em vez de um dado"8 (MEISTER; SCHÖNERT, 2009, p.23).

Como ler, por exemplo, um pequeno fragmento como este, escrito pelo romancista português António Lobo Antunes? Trata-se da visita a um hospital do tenente-coronel, um dos protagonistas do romance Fado Alexandrino (1983), quando é informado por dois funcionários, o "senhor Mendes" e o "diabético", do falecimento da sua esposa.

o senhor Mendes mirou-o a sério, torceu a boca solene, abriu-a para iniciar um discurso, fechou-a, abriu-a, fechou-a, ordenou por fim ao diabético Abra a porta ao senhor oficial para conversar à vontade. Porém nessa altura eu já tinha entendido e comecei a caminhar para a saída sem os olhar sequer, percebi que me chamavam ao longe Faz o obséquio faz o obséquio faz o obséquio, alcancei o jardim por intermédio de umas escaditas apertadas no extremo do edifício, onde um camponês de fato-macaco regava amorosamente os canteiros, e eu vazio (contava-me ele de cotovelos na toalha a acender um cigarro, esquecido do jantar), sem angústia, sem desgosto, sem aflição, sem nada, eu completamente oco a trotar frente as paredes usadas na direção do Volkswagen preto do quartel, eu a evitar tropeçar nas mangueiras, eu a galgar as plantas desmaiadas, eu a cruzar-me com os doentes e as visitas e as enfermeiras [...] eu a abrir a porta e a sentar-se no banco de trás, vi as pupilas interrogativas, instantaneamente despertas do condutor que dormitava ao volante no retângulo do espelho, Segue para os Anjos (ANTUNES, 2002, p.34).

\footnotetext{
7 "It is this interplay of time and tense, of the objectively perceived (or imagined) time-line and our subjectively experienced position-in-time which is so highly suggestive and lures us to immerse ourselves into a fictional continuum of events".

8 "Our attempt to answer the questions of 'where / who / how does s/he know / reflect / (dis-)inform'- has become an increasingly difficult task. There is no one narrative instance; rather, 'it' is something that is in flux and can change throughout every reading: it is a function, rather than a given".
} 
No princípio, um narrador, em terceira pessoa, relata o ensaio do "senhor Mendes" para noticiar a fatalidade, o mesmo narrador que, algumas linhas abaixo, entre parênteses, revela a sua própria visão do tenente ao relatar tal episódio anos depois: "contava-me ele de cotovelos na toalha a acender um cigarro, esquecido do jantar". A maior parte do excerto, no entanto, resulta diretamente do discurso do narrador-personagem em primeira pessoa, que também se distancia do passado e reflete: "e eu vazio, sem angústia... eu completamente oco a trotar...". Contudo, a maneira de contar em ambos os casos representa com nitidez o campo focalizado, ao optar por formas de tratamento utilizadas pelo tenente (o sr. Mendes, o diabético), ao descrever detalhes observados por ele (torceu a boca, abriu-a, fechou-a, escaditas apertadas, flores desmaiadas) e ao seguir o seu trajeto rápido e tonto do hospital até o carro, sugerindo os sentimentos envolvidos nessa percepção e permitindo ao leitor acompanhar muito de perto a perspectiva da personagem. No fragmento coexistem, pois, um centro dêitico narratorial ativo, com seu consequente efeito de atualidade do discurso, e um centro dêitico figural ativo, com seu consequente efeito de atualização da história, como se fossem "empilhados" planos mentais distintos. Em determinados trechos, no entanto, um ou outro foco se sobressai, deixando ocluído parcialmente os outros (como uma janela reduzida num ecrã de computador) e tornando "difícil ou mesmo irrelevante qualquer destrinça modal" (REIS, 2003, p.20). Certo é que a narrativa oscila entre as perspectivas do narrador (que também é personagem) e da personagem (também narradora), "em torno de um centro que todos partilham, mas ninguém assume em plenitude de direito" (JORGE, 2003, p.204). Certo ainda é que há um aproveitamento intenso e variegado de impressões e afetos, e a consequente exigência de um sempre alerta e disponível engajamento do leitor com a experiência representada. Na verdade, como a narrativa de Lobo Antunes parece dramatizar, os elementos dêiticos de um texto, indicadores criteriais de focalização, muitas vezes, implicam mais de uma origo, numa sobreposição ou justaposição de planos ontológicos que coexistem dialogicamente.

O caminho traçado até aqui apresenta uma rápida leitura avaliativa das principais e recentes linhas de abordagens da focalização, tentando desatar alguns dos nós dessa imbricada rede teórica. Esta torna-se uma tarefa imprescindível ao estudioso da literatura, sobretudo no momento em que as produções contemporâneas nos desafiam constantemente a extravasar limites e relativizar noções categóricas: diversidade de narradores, oscilação da voz e da perspectiva, rompimento das coordenadas espaço-temporais naturais, inderminação e suspeita quanto à origem da voz, sobreposição de pontos de vista, com razura irônica do discurso alheio, são estratégias recorrentes na narrativa do século XX e XXI. Sem falar na alimentação da narrativa literária por formas advindas de outros meios, como o cinema e a internet.

Assim, não é com uma simples separação entre quem vê e quem narra, ou com a classificação de focalização zero, interna ou externa, que compreendemos o processo de focalização de um texto. Seu modo de configuração interliga-se à figuração das personagens e do narrador, à percepção do espaço e do tempo. A qualidade das perspectivas representadas e a forma de coordená-las alimentam a densidade temática das pessoas ficcionais, a rede semântica e a tensão ideológica de um texto. A relação entre focalizador e objeto focalizado influencia na forma (e é influenciada pela forma) como o leitor se relaciona cognitiva, afetiva e axiologicamente com o texto. A própria releitura da concepção de literatura e da sua relação com outros saberes indica quão imprescindível é entender a focalização nas suas várias facetas, incluindo não somente a análise de articulações estruturais, mas também dos planos que matizam e diversificam qualitativamente tais articulações - psicológico, sociológico, fenomenológico, etc - em interação com o mundo extraliterário. 


\section{REFERÊNCIAS BIBLIOGRÁFICAS}

ANTUNES, António Lobo. Fado Alexandrino: Rio de Janeiro: Rocco, 2002.

BAL, Mieke. Narratology 3. ed. Toronto: University of Toronto Press, 2009.

BAKHTIN, Mikhail. Questões de literatura estética. 6 ed. São Paulo: Hucitec, 2010.

BOOTH, C. Wayne. A retórica da ficção. Trad. Maria Teresa H. Guerreiro. Lisboa: Arcádia, 1980.

CHATMAN, Seymor B. Coming to terms: the rethoric of narrative in fiction and film. Ithaca, NY: Cornell University Press, 1990.

COPLAN, Amy. Empathic engagement with narrative fictions. The Journal of Aesthetics and Art Criticism. Vol. 62, n. 2, Special Issue: Art, Mind, and Cognitive Science, 2004, p. 141152.

DECETY, Jean; JACKSON; Philip L. A Social-Neuroscience Perspective on Empathy. Current Directions in Psychological Science. Association for Psychological Science, 2006, vol. 15, n. 2.

DAMÁSIO, António. O livro da consciência. Trad. Luís Oliveira Santos. Lisboa: Círculo de Leitores, 2010.

FRIEDMAN, Norman. O ponto de vista na ficção. Trad. Fábio Fonseca de Melo. Revista USP, São Paulo, n. 53, p. 166-182, 2002. [1ª ed. 1967].

GENETTE, Gérard. Discurso da narrativa. Trad. Fernando Cabral Martins. 3.ed. Lisboa: Vega, 1995.

GENETTE, Gérard. Nuevo discurso del relato. Trad. Marisa Rodrígues Tapia. Madrid: Cátedra, 1998.

GERRIG, Richard J. Perspective as participation. In: PEER, Willie Van; CHATMAN, Seymor. New perspectives on narrative perspective. New York: State University of New York Press, 2001. p. $303-324$.

HERMAN, David. Beyond Voice and Vision: Cognitive Grammar and Focalization Theory. In: HÜNH, Peter et al. Point of view, perspective and focalization. Berlin/ New York: Walter de Ruyter, 2009, p. 119-142.

HERMAN, Luc; VERVAEC, Bart. Focalization between classical and postclassical narratology. PIER, J. The dynamics of narrative forms. Berlin/ New York: Walter de Ruyter, 2004. p. 115-138.

HÜNH, Peter; WOLF, Shimidt; SCHÖNERT, Jörg. Point of view, perspective and focalization. Berlin/ New York: Walter de Ruyter, 2009. 
JAHN, Manfred. "More Aspects of Focalization: Refinements and Applications". In: Pier, John (ed.). GRAAT: Revue des Groupes de Recherches Anglo-Américaines de L'Université François Rabelais de Tours, 1999, n. 21, p. 85-110.

JAMES, Henry. A arte do romance. Trad. Marcelo Pen. São Paulo: Globo, 2003.

JORGE, J. F. Carlos. A encenação de vozes quando todos falam. CABRAL, Eunice et al. (org.). A escrita e o mundo em António Lobo Antunes. Actas do Colóquio Internacional da Universidade de Évora. Lisboa: Dom Quixote, 2003. p. 195-205.

ISER, Wolfgang. $O$ ato da leitura. 1 ed. Trad. Johannes Kreschme. São Paulo: 34, 1999.

LUBBOCK, Percy. A técnica da ficção. Trad. Octávio Mendes Cajado. São Paulo: Cultrix, 1976.

MARGOLIN, Uri. Focalization: where do we go from here? In: HÜNH, Peter et al. Point of view, perspective and focalization. Berlin/ New York: Walter de Ruyter, 2009, p. 41-58.

MEISTER, Jan Christoph; SCHÖNERT, Jörg. The DNS of mediacy. In: HÜNH, Peter et al. Point of view, perspective and focalization. Berlin/ New York: Walter de Ruyter, 2009, p. 1140.

NIEDERHOFF, Burkhard. Focalization. The living handbook of narratology. Disponível em: < http://wikis.sub.uni-hamburg.de/lhn/index.php/Focalization > Acesso em: 16 abr. 2014.

NÜNNING, Ansgar. On the perspective Structure of narrative texts: steps toward a Constructivist Narratology. PEER, Willie Van e CHATMAN, Seymor. New perspectives on narrative perspective. New York: State University of New York Press, 2001. p. 207 - 224.

PEER, Willie Van; CHATMAN, Seymor. New perspectives on narrative perspective. New York: State University of New York Press, 2001. p.43-50.

PHELAN, James. Why narrators can be focalizers. In: PEER, Willie Van e CHATMAN, Seymor. New perspectives on narrative perspective. New York: State University of New York Press, 2001. p. 51-66.

PIMENTEL, Luz Aurora. 5. ed. Relato en perspectiva. México, DF: Siglo XXI, 2012.

PRINCE, Gerald. A point of view on point of view or refocusing focalization. In: PEER, Willie Van; CHATMAN, Seymor. New perspectives on narrative perspective. New York: State University of New York Press, 2001. p.43-50.

QUEIROZ, Eça de. Obra completa. Rio de janeiro: Aguilar, 1997. Vol. 1.

REIS, Carlos. António Lobo Antunes: uma casa de onde se vê o rio. CABRAL, Eunice et al. (org.). A escrita e o mundo em António Lobo Antunes. Actas do Colóquio Internacional da Universidade de Évora. Lisboa: Dom Quixote, 2003, p. 19-34. 
Recebido em: 15 de fevereiro de 2016.

Aceito em: 16 de junho de 2016. 